asHOKa

UNIVERSITY

Ashoka University Economics

Discussion Paper 50

\title{
The Distributional Impact of Climate Change: Why Food Prices Matter
}

\section{February 2021}

Eshita Gupta, Indian Statistical Institute, Delhi

Bharat Ramaswami, Ashoka University

E. Somanathan, Indian Statistical Institute, Delhi 


\title{
The Distributional impaCt of Climate CHANGE: WHY FOOD PRICES MATTER
}

\author{
Eshita Gupta* and Bharat Ramaswami ${ }^{\dagger}$ and E. Somanathan ${ }^{\ddagger}$
}

January 6, 2021

\begin{abstract}
We analyze the impact of agricultural productivity losses stemming from climate change in an economy without frictions. The first-order GDP impacts are expected to be small. But the poor have higher food budget shares and food prices will rise. How do distributional impacts diverge from the GDP impact? This is the question that is addressed. The paper considers two major sets of comparative statics: the effect of trade and the effect of economic growth. The model is calibrated to Indian data of 2009 and projections for 2030. The percentage loss of income for the landless is six times the GDP impact in a closed economy. Trade halves this effect and economic growth moderates it substantially. Despite the food price rise, nearly all farmers lose from climate change. The model is simple enough for impact channels to be transparent.
\end{abstract}

Keywords: Climate change, distribution, food prices, general equilibrium, India.

JEL codes: O13, O53, Q54

\footnotetext{
${ }^{*}$ Senior Research Fellow, Indian Statistical Institute, Delhi. At present working as a Technical Director, KPMG INDIA. E-mail: egupta13@gmail.com

†Professor, Department of Economics, Ashoka University, Sonepat, Haryana, India E-mail: bharat.ramaswami@ashoka. edu. in

${ }^{\ddagger}$ Professor, Economics and Planning Unit, Indian Statistical Institute, Delhi. E-mail: som@isid.ac.in
} 


\section{Introduction}

It is widely expected that climate change will be felt more severely in developing countries partly because of their tropical climate and partly because of the greater importance of weather driven economic activities, most notably, agriculture [Hertel \& Rosch, 2010]. This paper examines the economic impact because of the effect of climate change on agriculture.

It does not seem though that the GDP impacts of a climate-induced productivity shock on agriculture will necessarily be large. ${ }^{1}$ While agriculture's share in GDP is nearly $30 \%$ in the poorest economies (principally in Africa), the share is as low as $13 \%$ in the upper low income countries (principally in Asia) ([Bank, 2008]). The GDP impact may, however, not be the right metric to measure the welfare impacts of climate change. All low-income countries are characterized by shares of agriculture in employment that are higher than in GDP. In the poorest economies, agriculture accounts for about $65 \%$ of labor force. In the upper low income countries, this figure drops marginally to $57 \%$ ([Bank, 2008]). The impact on wages could therefore be a major potential source of welfare losses.

Another relevant fact is that the food budget shares are also large in poor economies. Comparing across different countries, [Pritchett \& Spivack, 2013], conclude that "the food share of the typical (median) household in the typical "low income" country is over 50 percent, is between 40 and 50 percent in "lower middle income" countries and 30 to 40 percent even in "upper middle income" countries." These numbers suggest that if climate change significantly impacts food prices, then that may also have major welfare impacts in poor countries.

Models of structural transformation have emphasized non-homothetic preferences arising from Engel's law as a key parameter that determines the effect of agricultural productivity on wages and prices (e.g., [Eswaran \& Kotwal, 1993], [Matsuyama, 1992]). In particular, such demand structures could exacerbate the losses from adverse impacts on agricultural productivity in poor countries.

For all of these reasons, it may be desirable to go beyond the metric of GDP in measuring the welfare losses from climate change. A case in point is India where the income share of agriculture is $15 \%$ (as against an employment share of nearly $50 \%$ ). We find from our review of the literature that climate change and ozone pollution decreased yields by $5.7 \%$ during the period 1980 to 2009. ${ }^{2}$ This means that the first-order income impact of climate change

\footnotetext{
${ }^{1}$ This is not to deny that the cumulative GDP losses in all sectors stemming from climate change can be large. See for instance, [Burke et al., 2015], [Kalkuhl \& Wenz, 2020]

${ }^{2}$ We consider ozone pollution together with climate change because the mitigation of each will have a great deal of overlap with the other - in both cases, greater energy efficiency and replacement of combustion with electrical energy from sources that do not involve combustion
} 
(in agriculture) was less than $1 \%$ of GDP. ${ }^{3}$ This is, however, misleading as a guide to the impact on economic welfare. Firstly, the share of food in consumption expenditures is, typically, well in excess of agriculture's share in GDP. In the case of India, food accounts for about $50 \%$ of consumption expenditures [GOI, 2009]. Therefore, the first order impact of the yield loss (in the period 1980-2009) on consumption and welfare would have been $2.8 \%$. However, even this will understate the welfare loss because the price of food will rise when its supply falls. Furthermore, as food budget shares are higher for the poor, the aggregate loss (even when adjusted for changing prices) may not be a good guide to the distribution of losses across income groups. The welfare effects would also differ between land owners (growing food) and those without land. The distinction is important because a substantial proportion of the workforce in India (as in many developing countries) still works in agriculture. While the landowners may gain from rising food prices, those with negligible or no land may lose from lower wages All of this demands that welfare impacts be analyzed within a general equilibrium framework. Therefore, past studies that quantify the impact of GDP loss (either using cross-sectional or panel data) are of limited value when assessing the impacts on economic welfare.

In this paper, we develop a stylized two-sector (food and non-food) general equilibrium framework in the tradition of structural transformation models (e.g., [Eswaran \& Kotwal, 1993], [Matsuyama, 1992]) for studying the impact of climate change on food prices and household welfare in India. The demand side is modelled by a preference structure rooted in Engel's law, according to which there is an inverse relationship between a household's income and its share devoted to food. The analysis is conducted separately under closed and open economy assumptions in order to judge the impact of trade. While price impacts need not be considered for small open economies, India is a large producer for many food commodities. ${ }^{4}$ Therefore, the model does not constrain India to be a small open economy. The simplicity of the model allows us to transparently assess the factors driving the results. The framework indicates how the initial conditions in terms of the level and distribution of wealth and land results in heterogeneity in a household's vulnerability to climate change in an economy.

The paper's contribution is its emphasis on the welfare impacts of climate change and its distribution. Existing analyses (as reviewed in the next section) have either not fully incorporated price impacts or done so in complex computable general equilibrium models.

\footnotetext{
${ }^{3}$ Such small impacts have also been found from more elaborate calculations. In a recent paper, [Roson \& Mensbrugghe, 2012] use a dynamic global general equilibrium model (ENVISAGE), to assess the economic consequences of climate change impacts. They find that the potential real GDP is expected to be lower in India by about 1\% in 2030 and about $2 \%$ in 2050 as compared to the counterfactual case with no climate change. [Bosello et al., 2012] find that the real GDP in India will be lower by $3.5 \%$ in 2050 as compared to a hypothetical scenario with no climate change.

${ }^{4}$ India accounts for about 20 percent of world rice production and 13 percent of world wheat production.
} 
This paper offers a tractable and transparent theoretical framework that can be applied to other 'large' developing countries where climate change can be expected to have price effects. A second contribution is to examine the role of trade in buffering the adverse impact of climate change. The third contribution of the paper is to compare the magnitude of climate impacts with those of food and non-food productivity growth and population growth in the medium term (till 2030).

The model is first calibrated to data from 2009. Drawing on the literature on climate change effects on yields, we find that if climate change and ozone pollution had not occurred, crop yields would have been higher by $5.7 \%$. The no-climate change scenario is our counterfactual. We seek to understand what aggregate economic welfare and its distribution would have been in the counter-factual relative to the baseline calibrated model. Compared to the first order impact of a $2.8 \%$ loss in consumption, we find that in a closed economy, allowing for the effect of food-price change increases the welfare loss by more than $50 \%$ to about $3.8 \%$ of consumption. In our model, the poorest agents are those without any cultivable land. They suffer the maximum loss in economic welfare amounting to $4.8 \%$ of their consumption in the counter-factual. Moreover, since most Indian farmers own very little land, nearly all of them are worse off as a result of climate change that lowers their productivity and raises the price of food. Only a small fraction of them gain from the resulting higher land rent.

These results are dramatically different in an open economy. The welfare losses are lower and the welfare of the poor declines by about the same proportion as the average impact which in turn is of the same order as the first order impact on consumption. These results are, of course, sensitive to the impact of climate change on crop yields in the rest of the world. We draw these estimates from the literature as well.

In surveying the literature on the poverty impacts of climate change, [Skoufias et al., 2011] point out that "Most estimates of the poverty impacts of climate change tend to ignore the effect of aggregate economic growth on poverty and household welfare." To address this gap, this paper calibrates the model to projected data for 2030. The main question of interest here is to assess the importance of climate change relative to other factors (productivity growth in the farm and non-farm sectors and population growth) in determining the welfare of the poor. We find that a combination of trade and economic growth can help buffer the poor against climate change. If the economy is closed, then improving the productivity of the agricultural sector has the greatest impact on the welfare of the poor. In contrast, if the economy is open, then the non-agricultural sector plays a bigger role in driving the welfare of the poor. The key implication of the analysis in this paper is that changes in productivity growth will have a much larger impact on the welfare of the poor than mitigation of climate change (unless climate impacts are larger than those considered in this study). 


\section{Relevant Literature}

While there is recent research suggesting adverse impacts of climate change on non-agricultural sectors ([Dell et al., 2013], [Hsiang et al., 2011], [Somanathan et al., 2015], [Burke et al., 2015]), our review here is limited to the impact on the agricultural sector.

The major impact of climate change in India on income is expected to come via losses in crop production. Looking at the impacts in the recent past, [Auffhammer et al., 2012] found that during 1966-2002 the rice yield was about 5.7\% lower due to climate change since the 1960s. [Gupta et al., 2016] found that wheat yields in India would have been higher in 2009 by $4.8 \%$ if climate had not changed during 1981-2009. In another study, wheat and rice yields are lower by $5.2 \%$ and $2 \%$ in India and by $5.5 \%$ and $0.1 \%$ in the world respectively, compared to yield projections without climate trends during the period 1980-2008 [Lobell et al., 2011].

Studies have also projected the impacts in India that will be realized in the future. [Mendelsohn et al., 2001] using a Ricardian approach, finds that climate change reduces yields by about 30-60\% in the long run (2080) relative to the1990s. [Rosenzweig \& Iglesias, 2006] using an agronomic crop model find that yields are expected to fall by about $14.3 \%$ in the long run (2080) relative to the 1990s due to climate change. [Guiteras, 2009] using annual panel data on yields and weather, projects that climate change over the period 2010-2039 will reduce major crop yields by 4.5 to $9 \%$, while in the long-run (2070-2099) and in the absence of adaptation yields are likely to fall by $25 \%$ or more relative to 1990 s. A recent study by [Kalkuhl \& Wenz, 2020] has estimated that an increase in global mean surface temperature by about $3.5^{\circ} \mathrm{C}$ by the end of the century is expected to reduce global food output by $7-14 \%$ in 2100, with relatively higher damages in tropical and poor regions. In addition to climate change, higher ozone concentrations are expected to reduce yields in 2030 over 2009 by $5-7 \%$ for India and by 2-3\% for the world ([Van Dingenen et al., 2009] , [Avnery et al., 2011]). Further, it is expected that $\mathrm{CO}_{2}$ fertilization is likely to increase global yields in the next 20 years at $1.8 \%$ per decade [Lobell \& Gourdji, 2012].

The estimates of the climate change impact on crop yields vary across studies due to different models and assumptions. [Gosling et al., 2011] provides an extensive review of studies done for India. While these studies are important to quantify the output loss due to climate change, we also need to estimate the impact of climate change on food prices if we want to obtain the effect of climate change on economic welfare. [Nelson et al., 2010] find that climate change will increase the number of malnourished children in 2050 relative to perfect mitigation by about 9-10 percent using the Impact model. Because Impact is a partial equilibrium model it cannot estimate directly the poverty effects of climate induced decline in agricultural productivity. [Costinot et al., 2016] use a representative agent model 
to examine the effect of trade on countries' welfare but do not deal with distributional effects. [Jacoby et al., 2015] quantifies the distributional impacts of climate change in rural India. Using a comparative static framework, the impact of climate change on household consumption is expressed as the impact of changes in temperature on returns to land and labor. The key idea is that food prices remaining constant, a fall in agricultural productivity leads to changes in returns to land and labor. In general equilibrium, however, a change in food prices also matters to wages and rentals and their model considers this impact as well. However, the Jacoby et.al model does not solve for equilibrium food prices. The study takes price changes from the projections of [Hertel et al., 2010]. Because the price changes are taken as exogenous, their model is not appropriate to study the role of trade as an adaptation mechanism. For instance, how do welfare impacts vary between a closed and an open economy? Such a question cannot be answered within the Jacoby et.al analysis. In addition, it is not clear whether the framework allows climate change in India to affect world food prices.

Trade effects are likely to be important because climate change is likely to have a more serious impact on tropical countries like India than on temperate countries. This shift in the geographic distribution of production is expected to result in a corresponding shift in trade flows ${ }^{5}$. [Fischer et al., 2002] estimate that by 2080 cereal imports by developing countries would rise by 10-40\%. Thus, the net economic effect of climate change on the agriculture of any country will depend as much on its role in agricultural trade as on the impacts of the changed climate on crop yields. [Reilly \& Hohmann, 1993] using static world policy simulation (SWOPSIM) model found that international trade will reduce the severity of climate change impacts on world agriculture and result in relatively small impacts on individual economies.

[Hertel et al., 2010] use a global computable general equilibrium trade model (the GTAP model) to examine the implications of climate-induced crop yield changes. Their paper, like ours, emphasizes the change in food prices and the varying impact it has on economic agents depending on their source of income. However, there are substantial differences in the research design. First, we allow labor to move across sectors in response to price changes, so that returns to labor and land are fully endogenized in our model. [Hertel et al., 2010], when examining poverty impacts, hold observed shares of income from labor and sale of food commodities fixed. Our paper thus allows agents a margin of adjustment in response to a change in the price of food that is absent in their paper. Since these adjustments take time, our paper is a longer-run analysis relative to [Hertel et al., 2010]. Second, we examine the

\footnotetext{
${ }^{5}$ [Huang et al., 2011] provides an extensive review of studies on climate change and trade in agriculture.
} 
effect of trade restrictions by comparing open and closed economy models, while they examine only the open economy. Third, we examine the moderating effect that economic growth has on the food price rise induced by climate change, which they do not. Fourth, they examine a large number of countries while we look only at India, which has the largest number of poor people of any country in the world. Our paper is thus complementary to theirs. We have a much less realistic model, that is much simpler and that can be solved analytically. This allows the reader to easily grasp the channels through which welfare effects operate. We find smaller effects on food prices than [Hertel et al., 2010] in our respective scenarios with severe climate change because they allow for imperfect substitutability between different food commodities while we have just one, and because they impose climate change on a 2001 economy, while we take into account the fact that the world and Indian economies will be considerably richer in 2030 .

Another paper complementary to ours is [Sedova et al., 2019]. This paper is also about the distributional incidence of climate change and contains an estimate of weather changes on the poor and the non-poor. Unlike us, the paper uses an econometric strategy of differencein-difference and presents reduced form estimates. Furthermore, the time period of analysis is shorter - from 2004/05 to 2011/12.

\section{The Model}

In our analysis, the economic effects of climate change flow from the impact on total factor productivity (TFP) in agriculture. The analysis takes this impact to be exogenous and as being determined by physical processes. The elasticity of agricultural TFP to climate change is denoted as $\sigma^{I}$ and $\sigma^{R}$ for India and the rest of the world, respectively. The model solves for the impact of agricultural TFP on food prices as a function of the elasticities $\sigma^{I}$ and $\sigma^{R}$.

\subsection{Closed economy case}

Consider an economy of $N$ individuals of which $N_{l}$ are in the labor force. The total land in the economy is denoted by $A$. Production functions in both food and non-food sectors exhibit constant returns to scale. The agricultural sector produces food $(F)$ using two inputs, land $\left(A_{F}\right)$ and labor $\left(L_{F}\right)$. The food production function is Cobb-Douglas:

$$
Y_{F}=\theta_{F} A_{F}^{1-\alpha} L_{F}^{\alpha}
$$

where $\theta_{F}$ is the total factor productivity in agriculture. The non-food sector using only labor $\left(L_{T}\right)$ produces a good that, for the sake of concreteness, we will refer to as textiles 
$(T)$. We use textiles as the numeraire good and we use $P$ to denote the price of food. The non-food production function is

$$
Y_{T}=\theta_{T} L_{T}
$$

where $\theta_{T}$ is the total factor productivity in non-agriculture. The linear technology means that the wage in terms of textiles is fixed:

$$
W=\theta_{T}
$$

Thus, market clearing conditions for land and labor are $A=A_{F}$ and $N_{l}=L_{F}+L_{T}$. We denote the wage rate by $W$, labor income per capita by $w=W N_{l} / N$ and per unit land rent by $r$. Using (1) and (3), we obtain labor demand in agriculture as

$$
L_{F}=A\left(\frac{\alpha P \theta_{F}}{\theta_{T}}\right)^{\frac{1}{1-\alpha}} .
$$

Labor market clearing implies

$$
L_{T}=N_{l}-A\left(\frac{\alpha P \theta_{F}}{\theta_{T}}\right)^{\frac{1}{1-\alpha}}
$$

We can write the equilibrium rent equation as

$$
r=\theta_{T}^{\frac{\alpha}{\alpha-1}}\left(\frac{1-\alpha}{\alpha}\right)\left(\alpha^{\frac{1}{1-\alpha}}\right)\left(P \theta_{F}\right)^{\frac{1}{1-\alpha}}
$$

On the consumption side, individuals are assumed to have identical Stone-Geary preferences, that are used to capture Engel's Law in a simple way. The utility function of an individual is

$$
U=(f-\underline{f})^{\rho}(t-\underline{t})^{1-\rho}
$$

with $0<\rho<1,(f-\underline{f})>0,(t-\underline{t})>0$.

Here, $f$ and $t$ represent total food consumption and non-food consumption of the individual, and $\underline{f}$ and $\underline{t}$ represent the subsistence food and non-food consumption. An individual maximizes utility subject to their income given by $M=w+r a$ where $a$ is the amount of land possessed by the individual. We obtain the demand for $F$ and $T$ by an individual as

$$
f=\underline{f}+\frac{\rho}{P}(w+r a-P \underline{f}-\underline{t})
$$




$$
t=\underline{t}+(1-\rho)(w+r a-P \underline{f}-\underline{t})
$$

Multiplying (8) by $P$, we see that $\rho$ is the proportion of the excess of income over subsistence consumption that is spent on food. It can also be seen that the demand functions are consistent with Engel's law - the budget share of food declines with income and that of non-food increases with income. As income becomes large, the food budget share declines and converges to $\rho$. On the other hand, when $\underline{f}$ and $\underline{t}$ are zero, the preferences are standard Cobb-Douglas and, therefore, homothetic. The expenditure on each commodity is linear in the excess of total expenditure over subsistence expenditure. We obtain total demand for $F$ and $T$ in this economy by adding demand functions of all the individuals. $F_{d}$ represents total food demand and $T_{d}$ represents total textiles demand.

$$
\begin{gathered}
F_{d}=\underline{f} N+\frac{\rho}{P}\left(w N+r A-P_{F} \underline{f} N-\underline{t} N\right), \\
T_{d}=\underline{t} N+(1-\rho)\left(w N+r A-P_{F} \underline{f} N-\underline{t} N\right),
\end{gathered}
$$

In general equilibrium, all four markets clear: $A=A_{F} ; N_{l}=L_{F}+L_{T} ; F_{d}=Y_{F} ; T_{d}=Y_{T}$. The market clearing condition for food can be dropped by Walras' law. We have already used the first two conditions. The general equilibrium of this closed economy is entirely determined by the solution to the remaining textile market clearing condition. Using (2), (3), (5), (6) and (11), we can write this equation only in $P$ and the exogenous parameters:

$$
\begin{aligned}
& \underline{t} N+(1-\rho)\left(\theta_{T} N_{l}+A\left(\theta_{T}^{\frac{\alpha}{\alpha-1}}\left(\frac{1-\alpha}{\alpha}\right)\left(P \theta_{F}\right)^{\frac{1}{1-\alpha}} \alpha^{\frac{1}{1-\alpha}}\right)-P \underline{f} N-\underline{t} N\right) \\
& =\theta_{T}\left(N_{l}-A\left(\frac{\theta_{T}}{\alpha P \theta_{F}}\right)^{\frac{1}{\alpha-1}}\right) .
\end{aligned}
$$

Totally differentiating (12) with respect to to $\theta_{F}$ and simplifying, we obtain the elasticity of the price of food with respect to the total factor productivity $\theta_{F}$. This is given by

$$
-\left(\frac{d P}{d \theta_{F}} \frac{\theta_{F}}{P}\right)=\varepsilon_{P \theta_{F}}=\frac{1}{1-\frac{f}{Y_{F}\left(1+\frac{\eta}{(1-\rho)}\right)}},
$$

where $\eta=\frac{\alpha}{1-\alpha}$. Note that, by assumption $\frac{f N}{Y_{F}}<1$ and $1-\rho>0$, so $\varepsilon_{P \theta_{F}}>1$. In a closed economy, the price of food rises more than proportionally with a decline in $\theta_{F}$. The elasticity of the price of food with respect to temperature is then just the product of the elasticity of the elasticity of the price of food with respect to the total factor productivity $\theta_{F}\left(\varepsilon_{P \theta_{F}}\right)$ 
and the elasticity of the total factor productivity $\theta_{F}$ with respect to temperature $\left(\sigma^{I}\right)$ and is given by

$$
-\left(\frac{d P}{d \tau} \frac{\tau}{P}\right)=\varepsilon_{P \tau}=\sigma^{I} * \varepsilon_{P \theta_{F}}=\frac{\sigma^{I}}{1-\frac{f}{Y_{F}\left(1+\frac{\eta}{(1-\rho)}\right)}},
$$

where $\tau$ is temperature.

Equation (14) relates the food price elasticity to the underlying demand and supply parameters. First, note that when $\underline{f}=0$, Engel's law is inoperative and the elasticity of food prices with respect to climate change is the same as the elasticity of TFP with respect to temperature. But when $\underline{f}>0$, Engel's law operates and food prices rise by a greater amount. More generally, higher is the share of minimum food consumption in total

food supply $\left(\frac{f N}{Y_{F}}\right)$, the greater will be the response of food prices to global warming $\left(\varepsilon_{P \tau}\right)$. This happens because even when productivity falls, demand for food cannot contract much because of subsistence requirements. Thus, to restore equilibrium, labor has to move from the non-food sector to the food sector. So the food price rise needed to induce a substantial share of the labor force to move to the food sector is correspondingly large. Hence, the Engel curve dynamics play an important role in determining the impact on food prices.

Second, if $\alpha$ is high, then so is $\eta$ and therefore the elasticity of food prices with respect to temperature will be low. This follows from the fact that $\alpha$ is the output elasticity of labor. So when this is high, any fall in agricultural productivity is easily met with a small shift of labor from the non-food sector to the food sector and therefore, the required rise in the price of food is small.

Finally, the higher is $\rho$ i.e., the proportion of excess income spent on food, the lower will be $\varepsilon_{P \tau}$. As noted earlier, the loss in agricultural productivity reduces incomes and demand for both goods. When $\rho$ is high, the percentage decline in food demand is much greater than when $\rho$ is low. Hence, the required sectoral shifts in labor and output are also smaller in the case when $\rho$ is high. Therefore, the food price increase is also smaller.

\subsection{Open economy case}

We now allow India to be an open economy. There are 2 economies- India $(I)$ and Rest of the World $(R)$. Both the economies have the same form of the production functions and utility functions as in the closed economy case but they differ with respect to labor endowments and production function parameters. In Appendix A, we derive the general equilibrium equation for $P$ in the open economy case. A readily interpretable special case is when the labor and 
land shares are the same across India and the rest of the world. Then we have

$$
-\left(\frac{d P}{d \tau} \frac{\tau}{P}\right)=-\varepsilon_{P \tau}=\frac{s^{I} \sigma^{I}+s^{R} \sigma^{R}}{1-\frac{f N^{G}}{\left(Y_{F}^{G}\right)\left(1+\frac{\eta}{(1-\rho)}\right)}}
$$

where $s^{I}$ is India's share in world food supply and $s^{R}$ is the share of the rest of the world in world food supply. Comparing (15) and (14), we see that they have a similar form. The numerator of (15) is the weighted average of TFP impact in India and the rest of the world while in the closed economy, the climate change in the rest of the world does not matter. The denominator of (15) is similar to that of (14), except that what matters now is the share of global subsistence needs in global food supply.

India being a tropical country, we expect $\sigma^{I}>\sigma^{R}$. Since climate change is expected to have a smaller effect on agricultural productivity in the rest of the world than it is in India, the net increase in the food price in India will be smaller than when the economy is closed. The global ratio of subsistence food consumption to food consumption is lower than the ratio in India. This is another reason why the elasticity of the food price with respect to climate change will be lower in the open economy. Quantifying the role of international trade as an adjustment mechanism is one of the key contributions of this study. The empirical simulations employ the general solution (in the appendix) rather than the special case (15).

\subsection{Welfare analysis}

We use equivalent variation as a measure of welfare change ${ }^{6}$. Equivalent variation (EV) is defined as the minimum amount of money that an individual is willing to receive to avoid a change in prices and income. In other words, EV satisfies $V(P, M+E V)=V\left(P^{\prime}, M^{\prime}\right)$ where $V$ is the indirect utility function. If $\mathrm{EV}$ is positive, the individual is better off with price and income change. If $\mathrm{EV}$ is negative, the individual is worse off with the price and income change. Using the expenditure function, the equivalent variation can be written as

$$
E V=e\left(P, V\left(P^{\prime}, M^{\prime}\right)\right)-M
$$

where $\mathrm{e}$ is the expenditure function. We are interested in the $\mathrm{EV}$ of a change in $\theta_{F}$ to $\theta_{F}^{\prime}$ because of climate change. A change in agricultural TFP results in a change in prices from $P$ to $P^{\prime}$ and a change in income from $w+r a$ to $w+r^{\prime} a$, both measured in terms of the

\footnotetext{
${ }^{6}$ We use Equivalent Variation (EV) and not Compensating Variation (CV) because EV is measured in base year prices and income. This makes it convenient to compare welfare across different scenarios each of which leads to different prices and incomes.
} 
numeraire textile good. ${ }^{7}$ From (7), (8), (9) and expenditure minimization we can derive the expression for the equivalent variation for an individual owning land $a$ as

$$
\begin{aligned}
E V & =\theta_{T}\left(\frac{N_{l}}{N}\right)\left[\left(\frac{P}{P^{\prime}}\right)^{\rho}-1\right]+(P \underline{f}+\underline{t})\left[1-\left(\frac{P}{P^{\prime}}\right)^{\rho}\right] \\
& -\frac{a}{\left(\theta_{T}\right)^{\frac{\alpha}{1-\alpha}}} \frac{1-\alpha}{\alpha} \alpha^{\frac{1}{1-\alpha}}\left[\left(\theta_{F} P\right)^{\frac{1}{1-\alpha}}-\left(\theta_{F}^{\prime} P^{\prime}\right)^{\frac{1}{1-\alpha}}\left(\frac{P}{P^{\prime}}\right)^{\rho}\right]
\end{aligned}
$$

Note that if $\left(\theta_{F} P\right)^{\frac{1}{1-\alpha}}<\left(\theta_{F}^{\prime} P^{\prime}\right)^{\frac{1}{1-\alpha}}\left(\frac{P}{P^{\prime}}\right)^{\rho}$ for $\theta_{F}^{\prime}<\theta_{F}$, then the second term is positive and the $\mathrm{EV}$ is increasing in land ownership. By putting $E V=0$, we obtain the cut-off level of land $\widehat{a}$ such that the individual is indifferent to the change:

$$
\widehat{a}=\frac{\theta_{T} \times\left(\frac{N_{l}}{N}\right)\left[\left(\frac{P}{P^{\prime}}\right)^{\rho}-1\right]+\underline{f} P-\underline{f} P^{\prime}\left(\frac{P}{P^{\prime}}\right)^{\rho}+\left[\underline{t}-\underline{t}\left(\frac{P}{P^{\prime}}\right)^{\rho}\right]}{\left(\theta_{T}\right)^{\frac{\alpha}{\alpha-1}}\left(\frac{1-\alpha}{\alpha}\right) \alpha^{\frac{1}{1-\alpha}}\left[\left(\theta_{F} P\right)^{\frac{1}{1-\alpha}}-\left(\theta_{F}^{\prime} P^{\prime}\right)^{\frac{1}{1-\alpha}}\left(\frac{P}{P^{\prime}}\right)^{\rho}\right]}
$$

Individuals with land ownership greater than $\widehat{a}$ gain from climate change and those with land ownership less than $\widehat{a}$ lose from climate change. The threshold level of land and the distribution of losses are calculated in the empirical simulation.

In the empirical analysis, the baseline is the observed economy and the counter-factual is the economy without the climate change. We report welfare change as the ratio of the change in $E V$ to income in the baseline. We report an unweighted average of these ratios. In addition, we also report an average of welfare changes using equity weights. Following the approach in [Anthoff \& Emmerling, 2019], weights are determined by the marginal utility of consumption. In our case, the weighted average takes a simple form: it is the simple average of the ratio of the change in EV to the excess of baseline income over subsistence. This expression is derived in Appendix B. Note that the unweighted average is also the equity weighted average when $\underline{f}=0$ and $\underline{t}=0$. Thus, Engel dynamics play a double role - they matter in determining the magnitude of price changes and they also matter in the evaluation of welfare outcomes.

\footnotetext{
${ }^{7}$ As noted earlier, the wage in terms of textiles is invariant to changes in agricultural TFP.
} 


\section{Data sources and method used for calibration}

\subsection{Endowments and Production Function Parameters}

The model is calibrated using data from 2009. Table 4.1 displays the list of production parameters, endowment variables, their calibrated values and the data sources used in the process. For both India and the world, the output of food in the production function is obtained from food balance sheets of the Food and Agriculture Organization (FAO) ${ }^{8}$. Total food output in calories is obtained by multiplying each food item by its calorific value and summing over all food items. We find that India's share in world calories is about $14 \%$. $\theta_{F}$ is obtained from the production function (1) given the values of food output $Y_{F}$, land $A$, labor employed in agriculture $L_{F}$, and $\alpha$ from Table 4.1. By Equation (3), productivity in the non-food sector is equal to the wage rate. Therefore, non-food productivity in India $\theta_{T}^{I}$ is taken to be the average wage of agricultural and non-agricultural workers. As we will see later, the non-food productivity in the rest of the world $\theta_{T}^{R}$ is solved from the general equilibrium of the open economy.

\subsection{Consumption parameters}

Table 4.2 displays the list of consumption parameters. First, we calculate the calorie price $P$, measured as an average household price from the consumption schedule of the National Sample Survey (2009). For each food item the National Sample Survey gives expenditure and quantity consumed. We calculate total calories consumed by each household using calorific values for each food item obtained from the National Sample Survey (2009). We calculate the food price for each household by dividing food expenditure of a household by food calories consumed. The average price for all the households is Rs .0104 per kcal. ${ }^{9}$

Second, we estimate the Stone-Geary linear food expenditure function using householdlevel data on consumption from the National Sample Survey (2009) by non-linear least squares to obtain the value of three unknown parameters $\underline{f}, \underline{t}$ and $\rho$. The equation estimated is

$$
\frac{P_{h} f_{h}}{n_{h}}=P_{h} \underline{f}+\rho\left(\frac{M_{h}}{n_{h}}-P_{h} \underline{f}-\underline{t}\right)+\varepsilon_{h}
$$

\footnotetext{
${ }^{8}$ The food items in the food balance sheets included cereals, pulses, sugarcrops, sugar and sweeteners, oilcrops, vegetable oils, vegetables, fruits, spices, stimulants (tea, coffee etc), alcoholic beverages, meat, animal fat, milk, and aquatic products.

${ }^{9}$ Outliers were dropped. The households with adult equivalent calorie consumption per day greater than 500 and less than 10000 were excluded.
} 
Table 4.1: Production Parameters (2009)

\begin{tabular}{llll}
\hline & Parameter & Value & Source \\
\hline \hline 1 & Annual Food output India $\left(Y_{F}^{I}\right)$ trillion calories/year & 1040 & Computed from FAO \\
2 & Annual Food output ROW $\left(Y_{F}^{R}\right)$ trillion calories/year & 6410 & Computed from FAO \\
3 & India's share in world calories $\left(\frac{Y_{F}^{I}}{\left(Y_{F}^{I}+Y_{F}^{R}\right)}\right)$ & $14 \%$ & Computed from FAO \\
4 & Gross cropped area India $\left(A_{F}^{I}\right)$ in million hectares & 195 & Land use statistics \\
5 & Arable and permanent crops land for ROW $\left(A_{F}^{R}\right)$ & 1338.35 & FAO \\
6 & India population $\left(N^{I}\right)$ in million & 1207.74 & FAO \\
7 & Work force Participation rate, India & .3966 & Censuses 2001 and 2011 \\
8 & $\%$ of total workers in agriculture, India & .49 & [GOI, 2009] \\
9 & Agriculture workers India $\left(L_{F}^{I}\right)$ million & 234.7 & Product of items 6,7,8 \\
10 & ROW population $\left(N^{R}\right)$ million & 5449.14 & FAO \\
11 & Work force Participation rate, ROW & .469 & [Bank, 2011] \\
12 & $\%$ of total workers in agriculture, ROW & .3456 & [Bank, 2011] \\
13 & Agriculture workers ROW $\left(L_{F}^{R}\right)$ million & 883 & Product of items 10,11,12 \\
14 & $\alpha$, share of labor in output for India & .46 & [Eswaran et al., 2007] \\
15 & $\alpha$, share of labor in output for ROW & .35 & [Alston et al., 2010] \\
16 & $\theta_{F}^{I}$, Productivity in the food sector in India & 4897500 & Using 1,4,12,14 (see text) \\
17 & $\theta_{F}^{R}$, Productivity in the food sector in ROW & 5539400 & Using 2,5,13,15 (see text) \\
18 & $\theta_{T}^{I}$, Productivity in the non-food sector in India $(\mathrm{Rs})$ & 30039 & [GOI, 2009]
\end{tabular}

Table 4.2: Consumption Parameters (2009)

\begin{tabular}{lll}
\hline Parameter & Value & Source \\
\hline \hline$P$ (Rs per Kcal) in the open economy & .0104 & Computed from NSSO (2009) \\
$\rho$ & .25 & Estimated from Non-linear Least squares \\
$\underline{f}$ (calories per day) adult equivalent & 1685 & Estimated from Non-linear Least squares \\
$\underline{t}$ & 0 & Estimated from Non-linear Least squares
\end{tabular}

where $P_{h}$ is the calorie price of the household $h, f_{h}$ denotes calories consumed by household $h, n_{h}$ is number of equivalent adults in household ${ }^{10} h, M_{h}$ represents total income of household $h$ as measured by the sum of food and non-food expenditure and $\varepsilon_{h}$ is the disturbance term. $\underline{f}$ and $\underline{t}$ are constrained to be non-negative. We obtain $\underline{f}$ as 61,5216 calories adult equivalent per year or 1685 calories adult equivalent per day, $\underline{t}$ as 0 and $\rho$ as 0.25 . These parameters are recorded in Table 4.2 .

\footnotetext{
${ }^{10}$ To determine adult equivalent reference scale we used the consumer unit (that is used as an indicator of the energy requirement of a group of persons of different sexes and ages in NSS 2009 nutrition intake report) weight 1 for male in the age group 20-39 as the norm. The average calorie requirements of males and females of other age groups are expressed as a ratio to this norm. The adult-equivalent fraction assigned to each individual varied from .43 for the new borns to 1.03 for males in the age group of 10 to12 years of age.
} 
Table 4.3: Calibrated Values from General Equilibrium

\begin{tabular}{lll}
\hline Parameter & Value & Source \\
\hline \hline$\theta_{T}^{R}$, Productivity in the non-food sector & 37,455 & Solved from General Equilibrium of Open Economy \\
$($ Rs) in rest of the world & & \\
$P$ (Rs per Kcal) in the closed economy & .0119 & Solved from General Equilibrium of Closed Economy
\end{tabular}

\subsection{General Equilibrium}

We assume that the observed food price of 0.0104 rupees/calorie is the price in the baseline open economy of 2009, that is, the economy in which climate change has occurred. Given the production and consumption parameters in Tables 4.1 and 4.2, the general equilibrium equation in the open economy (given in the Appendix) is used to solve for the only remaining unknown, i.e., productivity in the non-food sector of the rest of the world. This is displayed in Table (4.3). If the economy were closed, the equilibrium price would be different and we can no longer use the open economy price. For the closed economy, the general equilibrium condition in eq (12) is used to compute the equilibrium food price. This is shown in Table (4.3). We find that the price of food would be about 14 percent higher if the economy was closed to trade. The next section numerically simulates the responses of the open and closed economies to past climate and pollution trends.

\section{Impact of changes in climate and pollution during}

\section{0-2009}

In this section, we seek to understand the impact of historic climate change and pollution trends over a 30-year period (1980-2009) on food prices and welfare of the poor by comparing the economy calibrated to observed parameters to a counterfactual economy with no climate change. Table (5.1) provides information on estimated impacts on crop yields of past changes in climate and pollution. Based on the literature on climate change impacts, we derive the past loss in crop yields for India and the rest of the world by adding the estimated impacts of warming, $\mathrm{CO}_{2}$ fertilization, and ozone pollution, on crop yields.

For India, a $5.3 \%$ fall in $\theta_{F}$ during 1980-2009 is obtained by adding a 3.5 percent fall in yields (as estimated by [Lobell et al., 2011]) and a 4.7 percent fall in yields due to the ozone effect (obtained by backward projection of the estimated impact of ozone during 2000-2030 by [Van Dingenen et al., 2009]) to a 3 percent positive effect of $\mathrm{CO}_{2}$ fertilization (1.5 percent per decade as given in [Lobell \& Gourdji, 2012]). Similarly, we obtain a $2.5 \%$

decline in agricultural productivity for the rest of the world during 1980-2009. In case 
Table 5.1: Climate Impacts on Agricultural Productivity during 1980-2009

\begin{tabular}{lllll}
\hline Parameter & \multicolumn{2}{c}{ India } & Rest of the World \\
\hline \hline & $\%$ change & Source & \% change & Source \\
\hline Global Warming & -3.5 & [Lobell et al., 2011] & -3.1 & [Lobell et al., 2011] \\
$\mathrm{CO}_{2}$ fertilization & +3 & [Lobell \& Gourdji, 2012] & +3 & [Lobell \& Gourdji, 2012] \\
Ozone & -4.7 & [Van Dingenen et al., 2009]; & -2.4 & [Van Dingenen et al., 2009] \\
\hline \multicolumn{2}{r}{} & [Avnery et al., 2011] & [Avnery et al., 2011] \\
\hline Total & -5.3 & & -2.5 & \\
\hline
\end{tabular}

of ozone impacts, we find that there are limited past studies available and thus we have obtained a rough estimate for crop yield loss during 1980-2000 due to ozone pollution by projecting expected future changes ( during 2000-2030) backward till 1980. For instance, for India the studies by [Van Dingenen et al., 2009] and [Avnery et al., 2011] find that on average (over rice with $57 \%$ share and wheat with $43 \%$ share) crop yield losses due to ozone during 2000-2030 in India are likely to be about 2.34 percent per decade. As in the past, ozone concentrations would have been lower than in the present and future, we have assumed $4.7 \%$ loss in yields in India due to ozone over during 1980-2009 ${ }^{11}$.

\subsection{Closed Economy}

The closed economy equilibrium in calibrated (i.e., baseline) and counterfactual 2009 economies is described in the first two columns of Table 5.2. The yield loss due to climate change leads to a higher food price and higher rent per hectare than in the counterfactual with no climate change. The wage rate in terms of textiles is fixed but since workers spend part of their incomes on food, the real wage rate is lower when there is climate change.

The price and welfare impacts are presented in Figure 1. Four different welfare metrics are presented: a simple average of welfare changes of the landless as percentage of income, a simple average of all individuals as percentage of income, an average of welfare changes of landless using equity weights and an average of welfare changes of all individuals using equity weights. These metrics are used for all subsequent graphs as well.

As productivity in the agricultural sector falls, so does the food supply. In the closed economy case, the $5.3 \%$ decline in agricultural productivity $\theta_{F}$ relative to the counterfactual, results in a food price increase of about $8.3 \%$. With higher $P$, the marginal revenue product of labor increases in the agricultural sector and labor shifts from the non-food sector to the food sector. The labor force in the food sector $\left(L_{F}\right)$ increases by about $4.8 \%$. The

\footnotetext{
${ }^{11}$ We multiply 2.3 by 2 (resulting in $4.7 \%$ ) and not 3 for estimating the the likely impact of ozone on crop yields in India during past 3 decades 1980-2009. This is done as in the past ozone concentration would have been lower than in present. This is only a very rough estimate.
} 
Table 5.2: General Equilibrium in the Closed and Open Economies (2009)

\begin{tabular}{lllll}
\hline Variable & \multicolumn{2}{c}{$\begin{array}{c}\text { Closed } \\
\text { Economy }\end{array}$} & \multicolumn{2}{c}{$\begin{array}{c}\text { Open } \\
\text { Economy }\end{array}$} \\
\hline \hline & Counterfactual & Baseline & Counterfactual & Baseline \\
\hline \hline & No climate change & & No climate change & \\
Food Price (Rs/kcal) & .0110 & .0119 & .0099 & 0.0104 \\
Annual Wage Rate (Rs) & 30039 & 30039 & 30039 & 30039 \\
$\begin{array}{l}\text { Rent per hectare (Rs) } \\
\text { Food sector share (\%) }\end{array}$ & 27444 & 28770 & 22668 & 22180.5 \\
$\begin{array}{l}\text { Share of food in } \\
\text { expenditure of landless(\%) }\end{array}$ & 59.6 & 52 & 43.5 & 43.1 \\
$\begin{array}{l}\text { Food imports as \% } \\
\text { of food demand }\end{array}$ & - & 62.5 & 56 & 57.5 \\
$\begin{array}{l}\text { Non-Food exports as \% } \\
\text { of Non-food output }\end{array}$ & - & - & 11 & 14.4 \\
& & - & 9.5 & 12.6
\end{tabular}

unweighted average welfare declines by $3.8 \%$ and the equity weighted welfare declines by $7.3 \%$. By contrast, a naive partial equilibrium analysis would predict a real-income decline of only $2.8 \%$ when agricultural productivity declines by $5.7 \%$ and the food sector accounts for half the economy. Taking the food price rise into account increases the average welfare loss by more than one-third.

The labor force shifts are accompanied by a fall in real wages and an increase in land rents. Since wage and rental incomes move in opposite directions, there exists a threshold level of landholding above which an individual gains from the higher food price caused by from climate change. Figure 2 plots equivalent variation as percentage of income against land owned per adult equivalent. The threshold level of land is 0.94 hectares. More than $50 \%$ of Indians (adult equivalents) own no land or only a tiny amount of land (less than .009 hectares) and 90\% own less than 0.4 hectares (National Sample Survey 2009).

When the price of food increases, the real wage declines and, therefore, substitution and income effects work in the same direction for food for all but large landowners, and food consumption falls. For non-food demand, substitution and income effects work in opposite directions (except for large landowners) and the relative strength of the two effects determines the final consumption of non-food. The model quantifies these effects. For landless workers, the fall in $\theta_{F}$ of $5.3 \%$ leads to a decline in non-food consumption by about $7 \%$ and a decline in food consumption by about $3 \%$. As a result, their decline in welfare amounts to $4.8 \%$ of the income which is higher than the average welfare loss of 3.8\%. Moreoever, as subsistence expenditures account for much of their income, the equity weighted fall in welfare is much greater at $7.3 \%$ 
Figure 1: The Impact of Past Climate Change and Pollution in Closed and Open Economies on Welfare in 2009 Relative to a Counterfactual with no Climate and Pollution Change Over 1980-2009

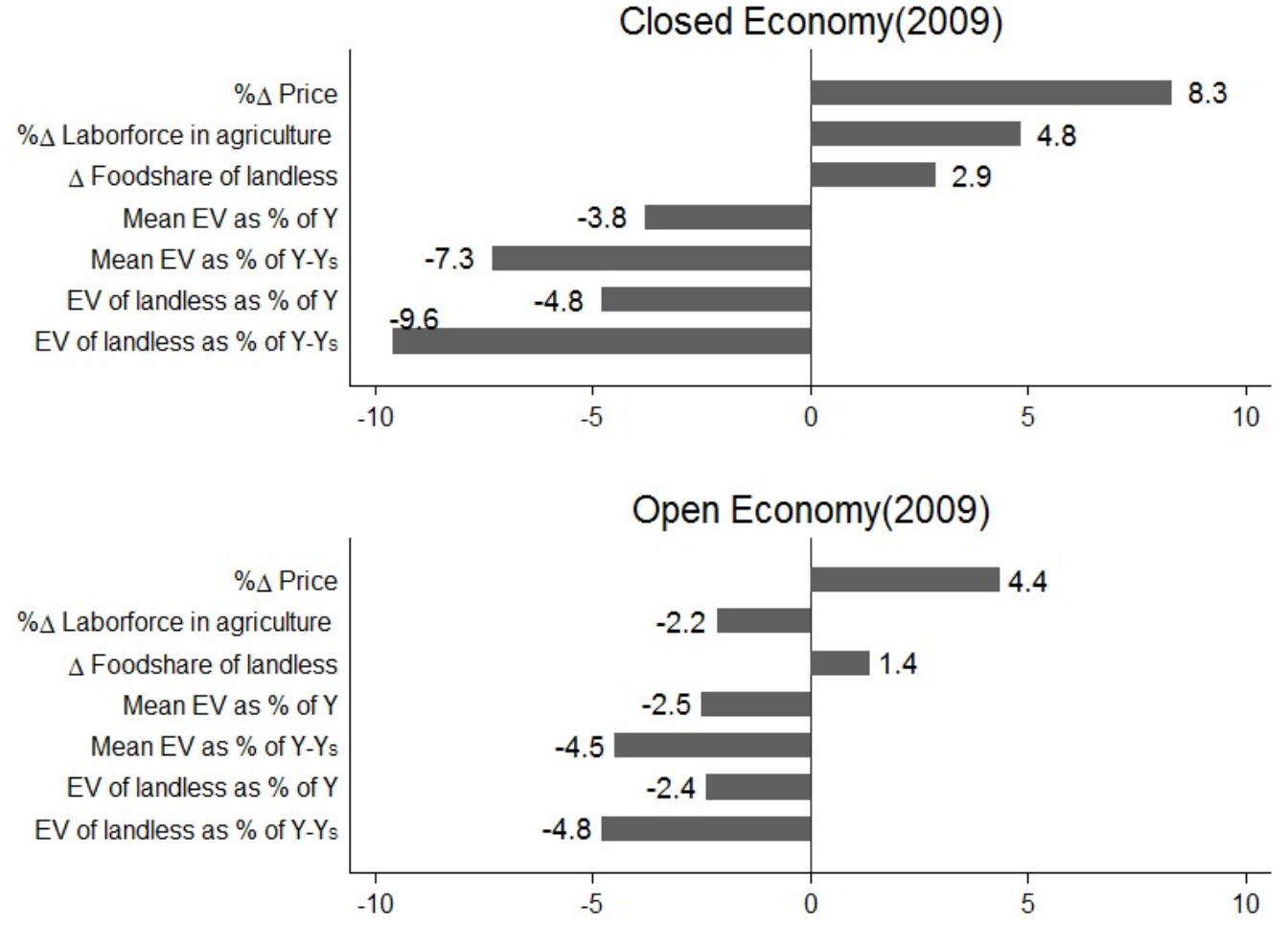

Note: $Y$ is Income. $Y_{S}$ is subsistence income. 
Figure 2: The Impact of Past Climate Change and Pollution in Closed and Open Economies by Land Ownership

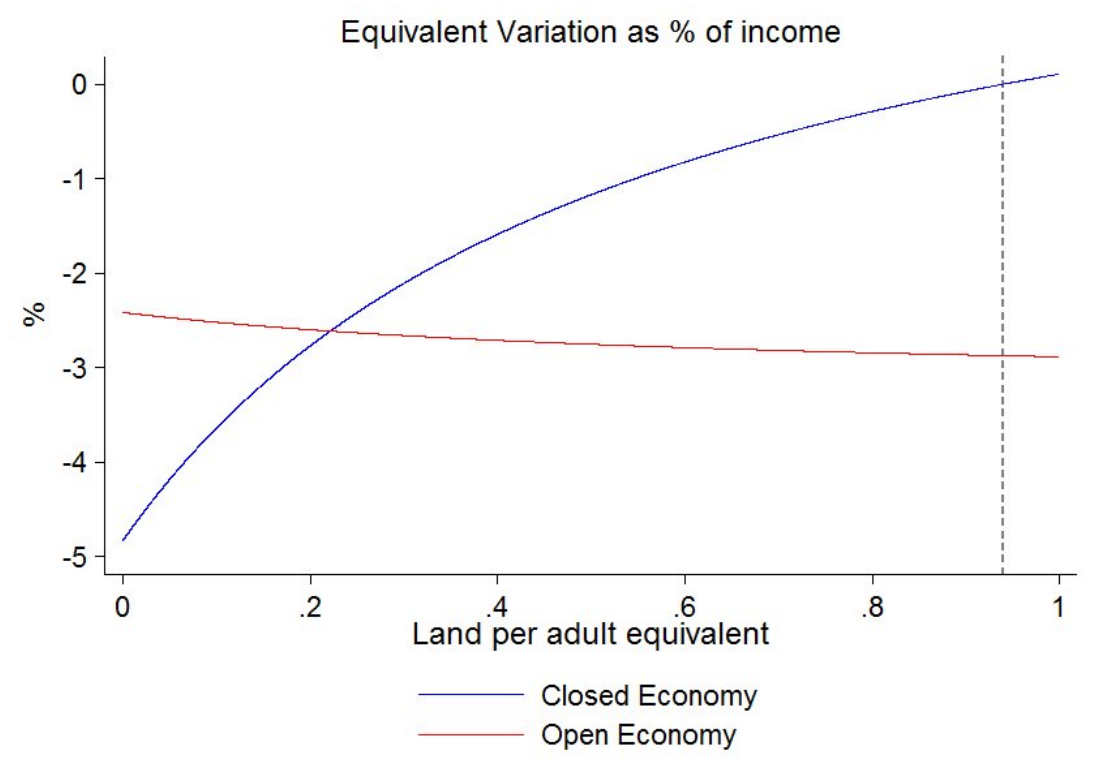

It is important to note that in the extreme case where the expenditure on subsistence food is zero, this difference in welfare loss due to climate change for a landless individual and average individual disappears. Also, the welfare loss is much lower at $1.4 \%$ of income. The price and welfare impacts in this case are presented in the appendix in Figure 5. These numbers illustrate clearly that ignoring general equilibrium effects, distribution and the Engel curve dynamics can greatly understate the welfare losses from global warming. The real income of the landless falls near one-for-one with declining food productivity even though the food sector constitutes only half the economy in the counterfactual scenario.

\subsection{Open economy}

The open economy equilibrium with and without climate change is described in the last two columns of Table 5.2. India imports about $14.4 \%$ of total food demand from the rest of the world in the baseline open economy and as a result, the equilibrium food price of Rs .0104 per calorie is about $15 \%$ lower than in the baseline closed economy. The sourcing of food from international markets decreases the share of the food sector in total output to $43 \%$ (as against $52 \%$ in the baseline closed economy). It decreases the share of workforce employed in the food sector to $26 \%$ from $33 \%$ in the baseline closed economy. As the non-food total factor productivity $\theta_{T}^{I}$ is the same in the closed and open economies, the annual wage rate (in terms of the numeraire) in the open economy remains the same as in the closed economy. 
However, rent per hectare falls because of lower food sector employment.

Figures 1 displays open economy results for the climate change scenarios. Food prices are $4.4 \%$ higher with climate change than in the counterfactual economy. The price impact is considerably smaller in the open economy as compared to the closed economy. For a landless person, the aveage fall in welfare amounts to $2.4 \%$ of income and the equity weighted fall is $4.8 \%$. Thus a landless individual is buffered from climate change in the open economy as compared to the closed economy. Moreover, unlike in the closed economy, their loss is of the same magnitude as that of the average individual. Figure 5 in the appendix plots the impacts if Engel dynamics were absent. Just like in the closed economy, the food price rise is lower and the adverse impacts are moderated.

As the gap between the percentage decline in agricultural productivity and the consequent percentage rise in food prices is lower in the open economy, land rents in India are lower relative to the counterfactual with no climate and ozone change. Figure 2 plots EV as percent of income against land held per adult equivalent. The equivalent variation is a decreasing function of landholding and is negative for all farmers. Thus, all farmers lose and in fact the large farmers lose more than the small farmers. The closed economy result is overturned because the increase in the food price is less than the fall in agricultural productivity and, therefore, rents fall. In this scenario (negative) EV for the small landholder of 0.1 hectares is Rs 428 and EV for a large landholder of 1.5 hectares is even more negative at Rs 1440 .

This result is similar to [Jacoby et al., 2011] which finds that in the most likely scenario of stable and falling food prices the welfare declines for the wealthiest households are marginally more severe than for the poorest. However, in their more pessimistic scenario for global food prices, wealthy households do a lot better and even gain from climate change.

It is important to note that the real economy impacts would be somewhere between the closed and open economy results since we observe trade in some agricultural commodities

such as oilseeds but not much in staples such as cereals. We conclude that food prices were 4 - 8 percent higher and the real income of the landless poor was $2.4-4.8$ percent lower relative to counterfactual without climate change and pollution (over past three decades) in 2009.

\section{Climate and Growth Impacts in 2030 Compared}

In this section, we examine how changes in climate and pollution will impact welfare in an economy calibrated to projected parameters in 2030. The main aim is to compare the impact of climate change to the impact of plausible variations in economic and population growth. 
Table 6.1: Annual Growth Rates of parameters for the Medium Growth Baseline Scenario assuming no further climate change between 2009 and 2030

\begin{tabular}{cccc}
\hline Variable & Region & Medium & Source \\
\hline \hline$N$ & India & $1.1 \%(0.8,1.38)$ & UNDP Forecasts \\
$\theta_{F}$ & India & $1.5 \%(0.75,2.25)$ & Bosworth and Collins $(2007)$ \\
$\theta_{T}$ & India & $3.04 \%(.66,1.21)$ & Bosworth and Collins (2007) \\
$N$ & Rest of the world & $.94 \%(.66,1.21)$ & UNDP Forecasts \\
$\theta_{F}$ & Rest of the world & $1.84 \%(.92,2.76)$ & Alston etal (2010) \\
$\theta_{T}$ & Rest of the world & $2.2 \%(1.1,3.3)$ & Bosworth and Collins (2003)
\end{tabular}

Note: Low and high scenarios are discussed in the brackets.

For all variables but population the low scenario has a growth rate that is $50 \%$ lower than in the medium scenario and the high scenario has a growth rate that is $50 \%$ higher than in the medium scenario.

\subsection{Growth Scenarios for the economy in 2009-2030.}

The parameter values used in the model for 2030 are the same as for 2009 except for population and total factor productivity in the food and the non-food sectors that are assumed to grow at rates taken from the literature. Table 6.1 presents the growth rate projections for these parameters and the sources from which they are drawn. The projections from the literature, including the UN's moderate population growth scenario, are our 'medium growth' scenario. We vary these growth rates one at a time to obtain 'low' and 'high' growth scenarios as follows. For population, we use the UN's high and low population growth scenarios. For the growth rates of food and non-food productivity we simply increase or decrease them by $50 \%$ (and round off). Appendix table D.1 shows values of important variables obtained in the calibrated general equilibrium in 2030 under the baseline medium growth scenario expressed as percentage changes from the 2009 values. ${ }^{12}$

\subsection{Climate and growth impacts in 2030}

We use the published literature to obtain the projected impacts of climate change on agricultural productivity in 2030 under two scenarios, one of moderate and one of severe climate change (and ozone pollution) between 2009 and 2030 (Table 6.2). The 5th Assessment Report of the IPCC projects a "likely" increase in mean surface temperature in South Asia between 1986-2005 and 2016-2035 of $1-1.5^{\circ} \mathrm{C}$ or $0.7-1^{\circ} \mathrm{C}$ every two decades ([IPCC, 2013],

\footnotetext{
${ }^{12}$ Although the closed and open economy do not differ in the rate of growth of food productivity, the relative price of food rises much more in the closed economy. For this reason, the real wage increase is greater in the open economy and the rise in land rent smaller.
} 
Table 6.2: Climate Impacts on Food Productivity in Moderate and Severe Scenarios, 20092030

\begin{tabular}{|c|c|c|c|c|c|c|}
\hline \multirow[t]{2}{*}{ Parameter } & \multicolumn{3}{|r|}{ India ( $\%$ change) } & \multicolumn{3}{|c|}{ Rest of the World (\% change) } \\
\hline & $\bar{M}$ & S & Source & $\bar{M}$ & $\overline{\bar{S}}$ & Source \\
\hline Global** & -5.5 & -11 & [Lobell et al., 2011] & -3 & -6 & [Lobell et al., 2011] \\
\hline Warming & & & & & & \\
\hline $\begin{array}{l}\mathrm{CO}_{2} \\
\text { fertilization }\end{array}$ & +3.6 & +3.6 & [Lobell \& Gourdji, 2012] & +3.6 & +3.6 & [Lobell \& Gourdji, 2012] \\
\hline Ozone** & -5 & -6 & [Van Dingenen et al., 2009] & -2.2 & -3.37 & [Van Dingenen et al., 2009] \\
\hline & & & [Avnery et al., 2011] & & & [Avnery et al., 2011] \\
\hline Total* & -7 & -13 & & -2 & 6 & \\
\hline
\end{tabular}

Note: M-Moderate scenario S-Severe scenario.

*The total impacts are rounded to the nearest integer value. ** For India we have taken weighted average of loss estimates for 2 major crops-wheat (with share 43\%) and rice (with share 57\%). For ROW we have taken weighted average of loss estimates for 3 major crops- wheat (with share 47\%), maize (with share $12.6 \%$ ) and rice (with share $40 \%$ ).

pp 1374-1375). ${ }^{13}$ Since the 2009-2030 period that we study is in the latter half of the IPCC period, it is reasonable to assume that the temperature increase will be at the upper end of the "likely" range. Thus, our moderate scenario assumes a $1^{\circ} \mathrm{C}$ increase in temperature between 2009 and 2030, while the severe scenario assumes a $2^{\circ} \mathrm{C}$ increase. The latter is meant to capture a worst-case assumption. Appendix B explains the construction of Table 6.2 in greater detail. The estimates from the literature cited in Table 6.2 imply a reduction in food productivity from the baseline of $7 \%$ in India and $2 \%$ in the rest of the world in the moderate scenario. In the severe scenario, these declines are $13 \%$ and $6 \%$ respectively.

The effects of these food productivity losses on the baseline 2030 economy in the medium growth scenario are shown in Figure 3. In the closed economy, the decline in food supply necessitates an expansion of employment in the food sector by $6 \%$ or $12 \%$ depending on the severity of climate change. Food prices have to rise to induce labor to move to agriculture. The $7 \%$ decline in $\theta_{F}$ in the moderate scenario increases food prices by almost $11 \%$. When $\theta_{F}$ declines by $13 \%$ in the severe scenario, food prices rise by $22 \%$. The average welfare loss is $4 \%$ of income and $6.8 \%$ of excess income over subsistence expenditure in the moderate scenario and $8.5 \%$ of income and $13 \%$ of excess income over subsistence expenditure in the severe scenario. The landless experience a larger welfare loss of $5.6 \%$ of income and $9 \%$ of excess income over subsistence expenditure in the moderate scenario and $11 \%$ of income and

\footnotetext{
13 "Likely" in IPCC terminology means the probability that the temperature increase will fall in this range is estimated to be about $2 / 3$. There is, therefore, a one-third chance that it is outside this range.
} 
$18 \%$ of excess income over subsistence expenditure in the severe scenario. We remark that although the food productivity decline of $7 \%$ is $23 \%$ larger than the one of $5.7 \%$ imposed on the 2009 economy, the negative impact on the real income of the landless is only $17 \%$ greater. This is because, as noted in Section 3.1, the share of the food sector is smaller in the richer economy of 2030, so a smaller share of the labor force has to move to the food sector to overcome any given shortfall, and so the necessary rise in the food price is smaller.

In the open economy, agricultural employment contracts with the food supply shortfall being met by imports and therefore price impacts are less severe. The welfare loss from climate change is also much smaller. The welfare loss of the landless is less than the average welfare loss. This result is driven by the decline in land rents owing to the decline in agriculture.

The effects of climate change in Table 6.2 can also be described in terms of reduced growth rates of food productivity in India and the rest of the world over the period 2009-2030. The annual growth rates of $\theta_{F}^{I}$ and $\theta_{F}^{R}$ growth are reduced by $0.36 \%$ and $0.1 \%$ respectively in the moderate scenario and by $0.67 \%$ and $0.3 \%$ in the severe scenario. We note that the variations in the growth rate of food productivity that we described above as 'plausible' exceed the declines brought about by climate change and pollution even in the severe scenario.

Besides the medium growth or baseline scenario, we consider 6 other scenarios. In these 6 scenarios, population and productivity in the rest of the world are assumed to grow at the medium rate. The variation then comes from what is assumed for population and TFP growth rates in India. In each of these scenarios, two of the variables are held to medium growth projections while the third variable is switched between high and low growth projections. For instance, the scenario titled high productivity in agriculture is one where agricultural TFP in India has the high growth rate while all other variables (non-agricultural TFP and population in India and all three variables in the rest of the world) follow medium growth projections. Appendix table D.2 summarizes these scenarios.

Figure 4 shows, for the closed and open economy, the real income of the landless poor in these seven scenarios of economic development for the 2030 economy. That is, 2030 income in 2009 prices is obtained by adding 2009 income and the equivalent variation of the change from 2009 to 2030. In each scenario, the length of the bar denotes the income of the landless in the absence of climate change between 2009 and 2030. The first break from the right in the bar shows what their income would be if there is moderate climate change ( $7 \%$ fall in $\left.\theta_{F}\right)$ and the second break from the right shows what landless income would be if there is severe climate change $\left(13 \%\right.$ fall in $\left.\theta_{F}\right)$.

The first outstanding fact of note is that in 2030, the landless poor are better off than in 2009 in all scenarios even with severe climate change. This is simply because we have 
Figure 3: Impact of Climate Change and Pollution from 2009-2030 on Welfare in Closed and Open Economies
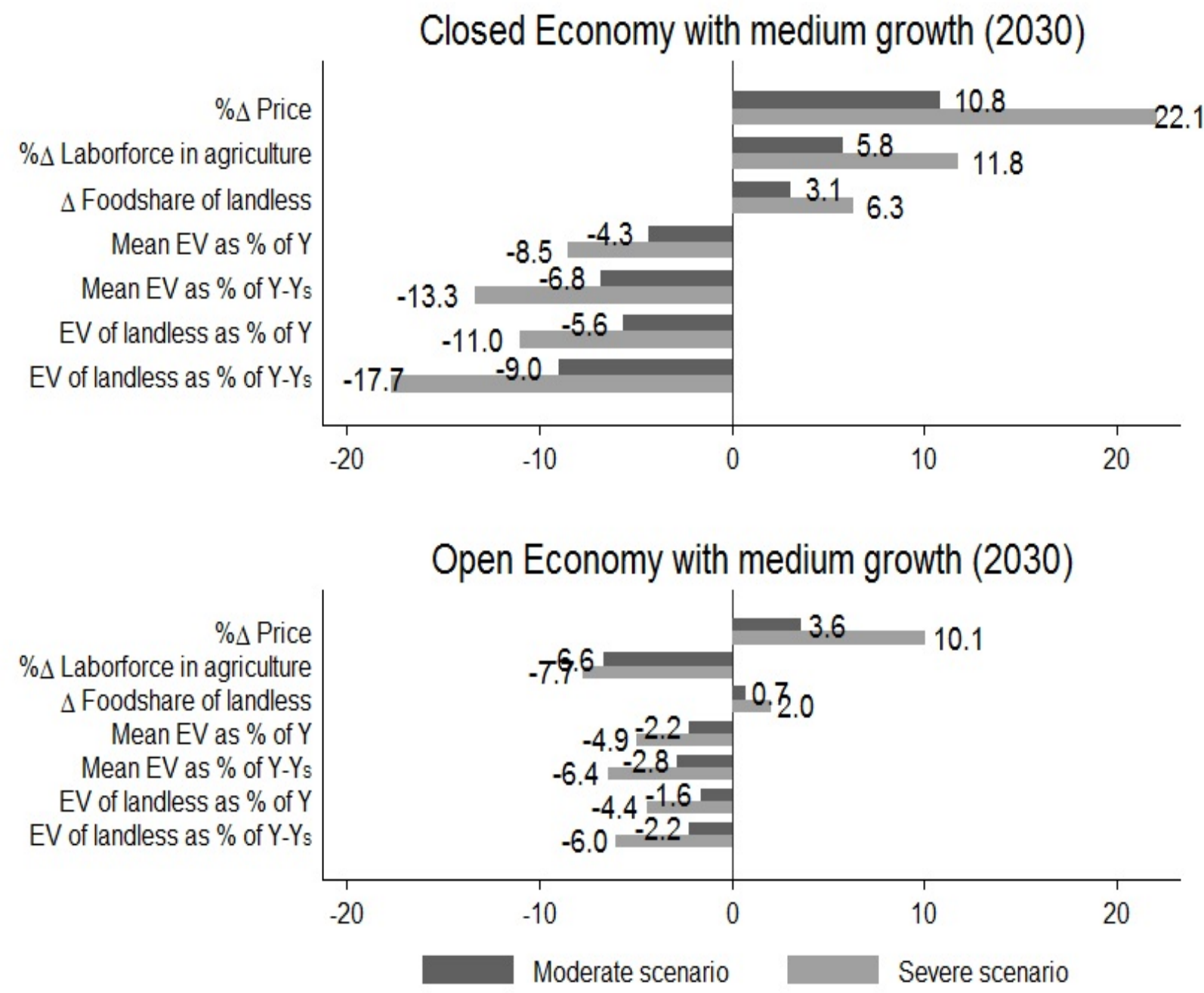

Note: $Y$ is Income. $Y_{S}$ is subsistence income.

Moderate scenario (dark bars) of $7 \%$ fall in $\theta_{F}^{I}$ and $2 \%$ fall in $\theta_{F}^{R}$ : Growth rate of agricultural productivity $\left(\theta_{F}^{I}\right)$ in India declines by $.36 \%$ p.a and in ROW $\left(\theta_{F}^{R}\right)$ declines by .1 p.a relative to no climate change medium growth scenario in 2030 .

Severe scenario (light bars) of $13 \%$ fall in $\left(\theta_{F}^{I}\right)$ and $6 \%$ fall in $\left(\theta_{F}^{R}\right)$ : Growth rate of agricultural productivity $\left(\theta_{F}^{I}\right)$ in India declines by $.67 \%$ p.a and in ROW $\left(\theta_{F}^{R}\right)$ by $.3 \%$ p.a relative to no climate change medium growth scenario in 2030 . 
Figure 4: Real Income of the Landless under Different Growth Paths in Closed and Open Economies
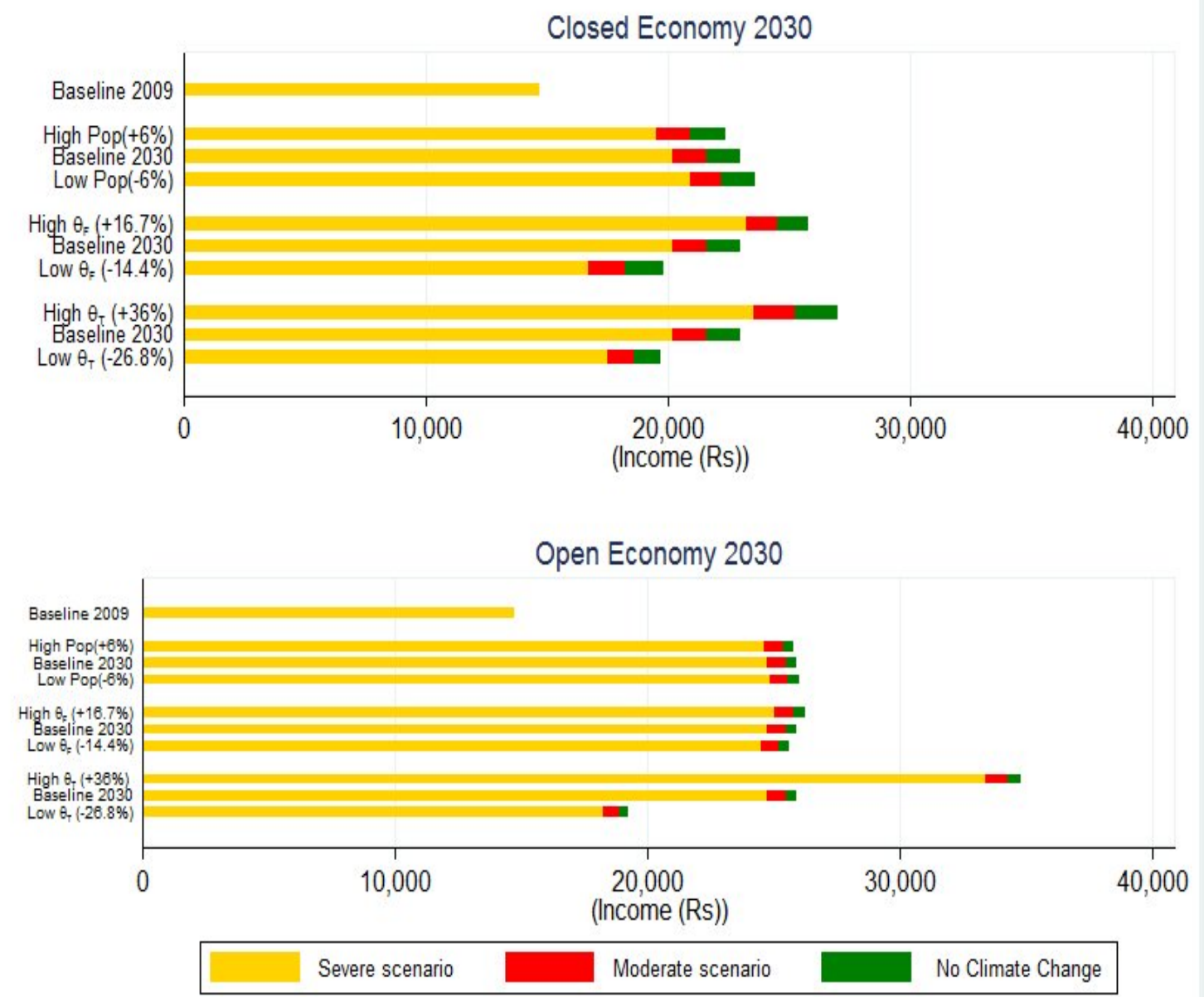

Note: Moderate scenario of $7 \%$ fall in $\theta_{F}^{I}$ and $2 \%$ fall in $\theta_{F}^{R}$ : Growth rate of agricultural productivity $\left(\theta_{F}^{I}\right)$ in India declines by $.36 \%$ p.a and in ROW $\left(\theta_{F}^{R}\right)$ declines by .1 p.a relative to no climate change medium growth scenario in 2030.

Severe scenario of $13 \%$ fall in $\left(\theta_{F}^{I}\right)$ and $6 \%$ fall in $\left(\theta_{F}^{R}\right)$ : Growth rate of agricultural productivity $\left(\theta_{F}^{I}\right)$ in India declines by $.67 \%$ p.a and in ROW $\left(\theta_{F}^{R}\right)$ by $.3 \%$ p.a relative to no climate change medium growth scenario in 2030 . 
assumed, in keeping with most of the literature, that climate effects are level effects and not growth effects. The second fact of note is that the effects of climate change are much smaller in the open than in the closed economy counterpart in each scenario because the opportunity to import food greatly moderates the rise in its price and thus protects the real income of the landless. The general equilibria of the closed and open economies are very different in their welfare impacts. The third result of note is that variation in non-food productivity $\left(\theta_{T}\right)$ growth has the largest effect on the income of the landless in both closed and open economies. This is because the projected growth rate in non-food productivity is higher than that of food productivity over these two decades, and so a $50 \%$ variation in it dominates variation in population or food productivity. We see that in the open economy, variation in non-food productivity has a much larger effect on the income of the landless than in the closed economy. Again, this is because imports moderate the rise in the food price that results from the higher food demand in an economy with a more productive non-food sector.

We note that climate impacts even in the moderate scenarios dominate population growth impacts in both open and closed economies. However, if the economy is closed, then plausible variations in agricultural productivity growth are larger than climate impacts in the moderate climate change scenario and similar to them in the severe scenario. If the economy is open, then climate impacts dominate the impacts of variation in $\theta_{F}^{I}$.

Another way to understand the relative importance of factors that determine the welfare of the poor is to derive the percentage change in the income of the poor in 2030 as a result of a $1 \%$ increase in food or non-food productivity or a $1 \%$ reduction in the population from the baseline medium growth scenario. When the economy is closed, we find that a $1 \%$ increase in food productivity is likely to increase the real income of the landless by $0.82 \%$ while a $1 \%$ increase in non-food productivity will increase the income of the landless by $0.51 \%$. A $1 \%$ decrease in population will increase the real income of the poor by about $0.45 \%$. Agricultural productivity, and, therefore, climate change has larger effects on the welfare of the poor than non-food sector growth, while demographic change also has significant effects.

In the open economy, a $1 \%$ increase in agricultural productivity over the baseline medium growth scenario increases the real income of the landless by only $0.08 \%$ over the baseline medium growth scenario. But, a $1 \%$ increase in non-food productivity increases landless incomes $0.96 \%$, almost one-for-one. In the 2030 economy, India accounts for $18 \%$ of the global food supply and imports $35 \%$ of its food. Higher agricultural productivity helps the poor by reducing food prices. However, since food prices fall by only a small amount this improves the welfare of the landless only marginally. On the other hand, higher non-agricultural productivity increases the real income of the poor by increasing wages directly and thus has 
a much bigger impact. Similarly, a 1\% lower population increases the income of the poor by only $0.06 \%$. Lower population impacts the poor indirectly by lowering food prices and thus has a much lower impact as in the case of agricultural productivity. If India can import its food without frictions from the rest of the world, improving non-agricultural productivity is likely to increase the welfare of the poor much more than improving agricultural productivity to reduce climate change impacts or spending resources in controlling population. Of course, these results would not be as stark in a model that accounts for diminishing returns to labor in the non-food sector.

\section{Conclusion}

Some of the key results of the study are as follows. First, most if not at all agents lose from climate change. Since most Indian farmers own very little land, they lose more from higher food prices than they gain. Those without land lose the most only the very few large landowners gain from higher food prices. In percentage terms, the welfare loss to the landless poor is five times greater than the first order impact on GDP if the economy is closed. Second, the buffering effect of international trade on the welfare of the poor is very important. The rise in food prices is moderated. Not only are the losses to the poor lower compared to the closed economy, the burden is also more uniformly distributed. All agents, including large landowners, lose and by about the same order of magnitude. It really matters to the poor what happens in the rest of the world. If climate change results in a large decline in agricultural productivity in the rest of the world as well, then food prices will rise significantly in the open economy and hurt the poor. Third, in the richer economy of 2030, the welfare impacts of climate change are less severe. Thus, climate is only one of the many factors that will shape food security and welfare of the poor in future.

The model has assumed there are no trade barriers. It is well known that world markets for grains are imperfect and government intervention keeps volumes lower than they would otherwise be [Anderson et al., 2013]. As India is a large country that affects world prices, the rest of the world may erect trade barriers if they wish to keep prices low for their population. This means that the real world outcome can be expected to be intermediate between the open and closed economy model outcomes.

More research is needed in future to study the welfare implications for the poor when the assumptions in our analysis fail to hold. This is beyond the scope of this paper but is an important issue of future research. While the quantitative investigation is geared to throw light on this issue for India, we expect the methodology of this research can be applied to other developing countries as well. 


\section{References}

[Alston et al., 2010] Alston, J. M., Babcock, B. A., \& Pardey, P. G. (2010). The shifting patterns of agricultural production and productivity worldwide. Midwest Agribusiness Trade Research and Information Center, Iowa State University.

[Anderson et al., 2013] Anderson, K., Rausser, G., \& Swinnen, J. (2013). Political economy of public policies: insights from distortions to agricultural and food markets. Journal of Economic Literature, 51(2), 423-477.

[Anthoff \& Emmerling, 2019] Anthoff, D. \& Emmerling, J. (2019). Inequality and the social cost of carbon. Journal of the Association of Environmental and Resource Economists, 6(2), 243-273.

[Auffhammer et al., 2012] Auffhammer, M., Ramanathan, V., \& Vincent, J. R. (2012). Climate change, the monsoon, and rice yield in india. Climatic change, 111(2), 411-424.

[Avnery et al., 2011] Avnery, S., Mauzerall, D. L., Liu, J., \& Horowitz, L. W. (2011). Global crop yield reductions due to surface ozone exposure: 2. year 2030 potential crop production losses and economic damage under two scenarios of pollution. Atmospheric Environment, 45(13), 2297-2309.

[Bank, 2008] Bank, W. (2008). World Development Report 2008. World Bank.

[Bank, 2011] Bank, W. (2011). World Bank Indicators 2011. Technical report, World Bank.

[Bosello et al., 2012] Bosello, F., Eboli, F., \& Pierfederici, R. (2012). Assessing the economic impacts of climate change. FEEM (Fondazione Eni Enrico Mattei), Review of Environment, Energy and Economics (Re3).

[Burke et al., 2015] Burke, M., Hsiang, S. M., \& Miguel, E. (2015). Global non-linear effect of temperature on economic production. Nature, 527(7577), 235-239.

[Costinot et al., 2016] Costinot, A., Donaldson, D., \& Smith, C. (2016). Evolving comparative advantage and the impact of climate change in agricultural markets: Evidence from 1.7 million fields around the world. Journal of Political Economy, 124(1), 205-248. 
[Dell et al., 2013] Dell, M., Jones, B. F., \& Olken, B. A. (2013). What Do We Learn from the Weather? The New Climate-Economy Literature. Technical report, National Bureau of Economic Research.

[Eswaran \& Kotwal, 1993] Eswaran, M. \& Kotwal, A. (1993). A theory of real wage growth in ldcs. Journal of Development Economics, 42(2), 243-269.

[Eswaran et al., 2007] Eswaran, M., Kotwal, A., Ramaswami, B., \& Wadhwa, W. (2007). How does poverty decline? Evidence from India, 1983-1999.

[Fischer et al., 2002] Fischer, G., Shah, M. M., \& Van Velthuizen, H. (2002). Climate change and agricultural vulnerability. IIASA, Laxenburg, Austria.

[GOI, 2009] GOI (2009). Employment and Unemployment Situation in India, Report no 53\%. Research reports, Government of India, Ministry of Statistics \& Programme Implementation.

[Gosling et al., 2011] Gosling, S. N., Dunn, R., Carrol, F., Christidis, N., Fullwood, J., Gusmao, D. d., Golding, N., Good, L., Hall, T., Kendon, L., et al. (2011). Climate: observations, projections and impacts. Climate: Observations, projections and impacts.

[Guiteras, 2009] Guiteras, R. (2009). The impact of climate change on indian agriculture. Manuscript, Department of Economics, University of Maryland, College Park, Maryland.

[Gupta et al., 2016] Gupta, R., Somanathan, E., \& Dey, S. (2016). Global warming and local air pollution have reduced wheat yields in india. Climatic Change, 139(3-4).

[Hertel et al., 2010] Hertel, T. W., Burke, M. B., \& Lobell, D. B. (2010). The poverty implications of climate-induced crop yield changes by 2030. Global Environmental Change, $20(4), 577-585$.

[Hertel \& Rosch, 2010] Hertel, T. W. \& Rosch, S. D. (2010). Climate change, agriculture, and poverty. Applied Economic Perspectives and Policy, 32(3), 355-385.

[Hsiang et al., 2011] Hsiang, S. M., Meng, K. C., \& Cane, M. A. (2011). Civil conflicts are associated with the global climate. Nature, 476(7361), 438-441.

[Huang et al., 2011] Huang, H., von Lampe, M., \& van Tongeren, F. (2011). Climate change and trade in agriculture. Food Policy, 36, S9-S13. 
[IPCC, 2013] IPCC (2013). Working group i contribution to the ipcc fifth assessment report climate change 2013: The physical science basis. Intergovernmental Panel on Climate Change.

[Jacoby et al., 2011] Jacoby, H., Rabassa, M., \& Skouas, E. (2011). Distributional implications of climate change in india. World Bank Policy Research Working Paper Series, Vol.

[Jacoby et al., 2015] Jacoby, H. G., Rabassa, M., \& Skoufias, E. (2015). Distributional implications of climate change in rural india: A general equilibrium approach. American Journal of Agricultural Economics, 97(4), 1135-1156.

[Kalkuhl \& Wenz, 2020] Kalkuhl, M. \& Wenz, L. (2020). The impact of climate conditions on economic production. evidence from a global panel of regions. Journal of Environmental Economics and Management, 103, 102360.

[Lobell \& Gourdji, 2012] Lobell, D. B. \& Gourdji, S. M. (2012). The influence of climate change on global crop productivity. Plant physiology, 160(4), 1686-1697.

[Lobell et al., 2011] Lobell, D. B., Schlenker, W., \& Costa-Roberts, J. (2011). Climate trends and global crop production since 1980. Science, 333(6042), 616-620.

[Matsuyama, 1992] Matsuyama, K. (1992). Agricultural productivity, comparative advantage, and economic growth. Journal of economic theory, 58(2), 317-334.

[Mendelsohn et al., 2001] Mendelsohn, R., Dinar, A., \& Sanghi, A. (2001). The effect of development on the climate sensitivity of agriculture. Environment and Development Economics, 6(1), 85-101.

[Nelson et al., 2010] Nelson, G. C., Rosegrant, M. W., Palazzo, A., Gray, I., Ingersoll, C., Robertson, R., Tokgoz, S., Zhu, T., Sulser, T. B., Ringler, C., \& Msangi, S. a. (2010). Food security, farming, and climate change to 2050: Scenarios, results, policy options. Research reports Gerald C. Nelson, et al., International Food Policy Research Institute (IFPRI).

[Pritchett \& Spivack, 2013] Pritchett, L. \& Spivack, M. (2013). Estimating Income/Expenditure Differences Across Populations: New Fun with Old Engel's Law. Technical Report 339, Center for Global Development.

[Reilly \& Hohmann, 1993] Reilly, J. \& Hohmann, N. (1993). Climate change and agriculture: the role of international trade. The American Economic Review, 83(2), 306-312. 
[Rosenzweig \& Iglesias, 2006] Rosenzweig, C. \& Iglesias, A. (2006). Potential impacts of climate change on world food supply: data sets from a major crop modeling study. Goddard Institute for Space Studies, Columbia University, New York.

[Roson \& Mensbrugghe, 2012] Roson, R. \& Mensbrugghe, D. V. d. (2012). Climate change and economic growth: impacts and interactions. International Journal of Sustainable Economy, 4(3), 270-285.

[Sedova et al., 2019] Sedova, B., Kalkuhl, M., \& Mendelsohn, R. (2019). Distributional impacts of weather and climate in rural india. Economics of Disasters and Climate Change, (pp. 1-40).

[Skoufias et al., 2011] Skoufias, E., Rabassa, M., \& Olivieri, S. (2011). The poverty impacts of climate change: a review of the evidence. World Bank Policy Research Working Paper Series.

[Somanathan et al., 2015] Somanathan, E., Somanathan, R., Sudarshan, A., \& Tewari, M. (2015). The Impact of Temperature on Productivity and Labor Supply: Evidence from Indian Manufacturing. Technical report, Indian Statistical Institute, Delhi.

[Van Dingenen et al., 2009] Van Dingenen, R., Dentener, F. J., Raes, F., Krol, M. C., Emberson, L., \& Cofala, J. (2009). The global impact of ozone on agricultural crop yields under current and future air quality legislation. Atmospheric Environment, 43(3), 604-618.

\section{APPENDICES}

\section{A Model derivation}

\section{A.1 Closed economy case}

Totally differentiating eq(12) with respect to to $\theta_{F}$ and simplifying, we obtain the elasticity of the price of food with respect to the total factor productivity $\theta_{F}$.

$$
-\left(\frac{d P}{d \theta_{F}} \frac{\theta_{F}}{P}\right)=\varepsilon_{P \theta_{F}}=\left[\frac{\left(\frac{1-\alpha}{\alpha}+\frac{1}{1-\rho}\right) Y_{F}\left(\frac{\alpha}{1-\alpha}\right)}{\left(\frac{1-\alpha}{\alpha}+\frac{1}{1-\rho}\right) Y_{F}\left(\frac{\alpha}{1-\alpha}\right)-\underline{f} N}\right]=\frac{1}{1-\frac{\underline{f} N}{Y_{F}\left(1+\frac{\eta}{(1-\rho)}\right)}}
$$

\section{A.2 Open economy case}

We assume that the factor markets clear locally and the goods market clear internationally. The total food production is given as $Y_{F}=Y_{F}^{I}+Y_{F}^{R}$. 
Here,

$$
Y_{F}^{I}=\theta_{F}^{I} A_{F}^{I}\left(\frac{L_{F}^{I}}{A_{F}^{I}}\right)^{\alpha}
$$

for $I$ and

$$
Y_{F}^{R}=\theta_{F}^{R} A_{F}^{R}\left(\frac{L_{F}^{R}}{A_{F}^{R}}\right)^{\beta}
$$

for $R$.

Similarly, the total non-food production is given as $Y_{T}=Y_{T}^{I}+Y_{T}^{R}$. Here $Y_{T}^{I}=\theta_{T}^{I} L_{T}^{I}$ for $I$ and $Y_{T}^{R}=\theta_{T}^{R} L_{T}^{R}$ for $R$. Factor market clearing conditions for land and labor for $I$ are $N_{l}^{I}=L_{F}^{I}+L_{T}^{I}$ and $A^{I}=A_{F}^{I}$. Similarly for $R$ we have $N_{l}^{R}=L_{F}^{R}+L_{T}^{R}$ and $A^{R}=A_{F}^{R}$. We denote the wage rate by $W^{I}$ in $I, w^{I}$ per capita wage in $I, w^{R}$ per capita wage in $R$ and by $W^{R}$ in $R$. We denote per unit land rent by $r^{I}$ in $I$ and by $r^{R}$ in $R$.

On consumption side, as previously we have

$$
U_{i}^{I}=\left(f_{i}^{I}-\underline{f}\right)^{\rho}\left(t_{i}^{I}-\underline{t}\right)^{1-\rho}
$$

for $I$ and

$$
U_{i}^{R}=\left(f_{i}^{R}-\underline{f}\right)^{\rho}\left(t_{i}^{R}-\underline{t}\right)^{1-\rho}
$$

for $R$. Individuals in both regions maximize utility subject to their respective income constraints $M_{i}^{I}=w^{I}+r^{I} a_{i}$ for $I$ and $M_{i}^{R}=w^{R}+r^{R} a_{i}$ for $R$. As in the previous section we can derive total demands of $F$ and $T$ in both the economies in the following way:

$$
\begin{gathered}
F_{d}^{I}=\underline{f} N^{I}+\frac{\rho}{P}\left(w^{I} N_{l}^{I}+r A^{I}-P \underline{f} N^{I}-\underline{t} N^{I}\right) \\
F_{d}^{R}=\underline{f} N^{R}+\frac{\rho}{P}\left(w^{R} N_{l}^{R}+r A^{R}-P \underline{f} N^{R}-\underline{t} N^{R}\right)
\end{gathered}
$$

Global food demand is obtained as $F_{d}=F_{d}^{I}+F_{d}^{R}$

Similarly, for non-food we have

$$
\begin{gathered}
T_{d}^{I}=\underline{t} N^{I}+(1-\rho)\left(w^{I} N_{l}^{I}+r^{I} A^{I}-P \underline{f} N^{I}-\underline{t} N^{I}\right) \\
T_{d}^{R}=\underline{t} N^{R}+(1-\rho)\left(w^{R} N_{l}^{R}+r^{R} A^{R}-P \underline{f} N^{R}-\underline{t} N^{R}\right)
\end{gathered}
$$

Global non-food demand is obtained as $T_{d}=T_{d}^{I}+T_{d}^{R}$

As in the closed economy case, we obtain optimal labor, rent and output supply from marginal conditions in both sectors of the respective economies. 
In general equilibrium, all four markets clear.Land: $A^{I}=A_{F}^{I} ; A^{R}=A_{F}^{R}$;labor: $N_{l}^{I}=$ $L_{F}^{I}+L_{T}^{I} ; N_{l}^{R}=L_{F}^{R}+L_{T}^{R}$; Food: $F_{d}=F_{d}^{I}+F_{d}^{R}=Y_{F}=Y_{F}^{R}+Y_{F}^{I}$

Textile: $T_{d}=T_{d}^{I}+T_{d}^{R}=Y_{T}=Y_{T}^{R}+Y_{T}^{I}$

As shown previously general equilibrium can be obtained with textile market equilibrium condition as follows: $T_{d}=T_{d}^{I}+T_{d}^{R}=Y_{T}=Y_{T}^{R}+Y_{T}^{I}$

$$
\begin{aligned}
& \left(\theta_{T}^{I^{\frac{\alpha}{\alpha-1}}}\left(\frac{1-\alpha}{\alpha}\right) P \theta_{F}^{I \frac{1}{1-\alpha}} \alpha^{\frac{1}{1-\alpha}}\right) A^{I}-P \underline{f} N^{I}+\left(\theta_{T}^{R^{\frac{\beta}{\beta-1}}}\left(\frac{1-\beta}{\beta}\right) P \theta_{F}^{R \frac{1}{1-\beta}} \beta^{\frac{1}{1-\beta}}\right) A^{R}-P \underline{f} N^{R} \\
& +\frac{1}{(1-\rho)} A^{I}\left(\frac{\theta_{T}^{I}}{\alpha P \theta_{F}^{I}}\right)^{\frac{1}{\alpha-1}}+\frac{1}{(1-\rho)} A^{R}\left(\frac{\theta_{T}^{R}}{\beta P \theta_{F}^{R}}\right)^{\frac{1}{\beta-1}} \\
& =\frac{\rho \theta_{T}^{I} N^{I}+\rho \theta_{T}^{R} N^{R}-\rho \underline{t} N^{I}-\rho \underline{t} N^{R}}{(1-\rho)}
\end{aligned}
$$

From the above equation we determine equilibrium international price of food $P$.Also, we can get food price elasticity in the open economy as

$$
\begin{aligned}
-\left(\frac{d P}{d \tau} \frac{\tau}{P}\right) & =-\varepsilon_{P \tau}=\frac{s^{I} \varepsilon\left(\theta_{F}^{I} \tau\right)\left(\frac{\eta^{I}}{1-\rho}+1\right)+s^{R} \varepsilon\left(\theta_{F}^{R} \tau\right)\left(\frac{\eta^{R}}{1-\rho}+1\right)}{1+s^{I}\left(\frac{\eta^{I}}{1-\rho}\right)+s^{R}\left(\frac{\eta^{R}}{1-\rho}\right)-\frac{f\left(N^{G}\right)}{\left(Y_{F}^{G}\right)}} . \\
& =\frac{s^{I} \varepsilon\left(\theta_{F}^{I} \tau\right)+s^{R} \varepsilon\left(\theta_{F}^{R} \tau\right)}{1-\frac{f\left(N^{G}\right)}{\left(Y_{F}^{G}\right)\left(1+\frac{\eta}{(1-\rho)}\right)}} \text { if } \eta^{I}=\eta^{R} .
\end{aligned}
$$

\section{B Derivation of equity weights for utilitarian social welfare}

Suppose the social welfare function $W\left(v_{1}, \ldots v_{n}\right)$ is utilitarian so that $W=\sum_{i} v_{i}\left(P, m_{i}\right)$ where $v_{i}$ is the indirect utility function of individual $i$. Then, for any vector of small changes in incomes $\left(d m_{1}, \ldots d m_{n}\right)$, the change in social welfare is

$$
d W=\sum \frac{\partial v_{i}}{\partial m_{i}} d m_{i}
$$

For convenience, we use the log transformation of Stone-Geary utility in what follows. Now

$\frac{\partial v_{i}}{\partial m_{i}}$ is the marginal utility of money, so by the first-order condition for utility maximization 
with respect to food

$$
\begin{aligned}
\frac{\partial v_{i}}{\partial m_{i}} & =\frac{\partial \log U}{\partial f_{i}} \\
& =\frac{\rho}{P\left(f_{i}-\underline{f}\right)} \\
& =\frac{1}{P\left(f_{i}-\underline{f}\right)+\left(t_{i}-\underline{t}\right)}
\end{aligned}
$$

The last step follows from Equation (8) because $\rho$ is the excess of expenditure on food over the subsistence level of food expressed as a share of the excess of total expenditure over subsistence expenditure. This is the analogue for Stone-Geary utility of the constant expenditure shares of Cobb-Douglas utility.

Thus, an exact measure of the change in social welfare from a vector of changes in incomes is their sum expressed as percentages of the excess of income (= expenditure) over subsistence income. That is, equity weights are the reciprocals of the differences of incomes over subsistence income. For more detailed discussion on equity weights please see [Anthoff \& Emmerling, 2019].

\section{Model results with Homothetic preferences}

We present the results of the model when subsistence expenditure is zero, that is, when preferences are homothetic, in Figure 5 below. 
Figure 5: The Impact of Past Climate Change and Pollution in Closed and Open Economies on Welfare in 2009 Relative to a Counterfactual with no Climate and Pollution Change Over 1980-2009
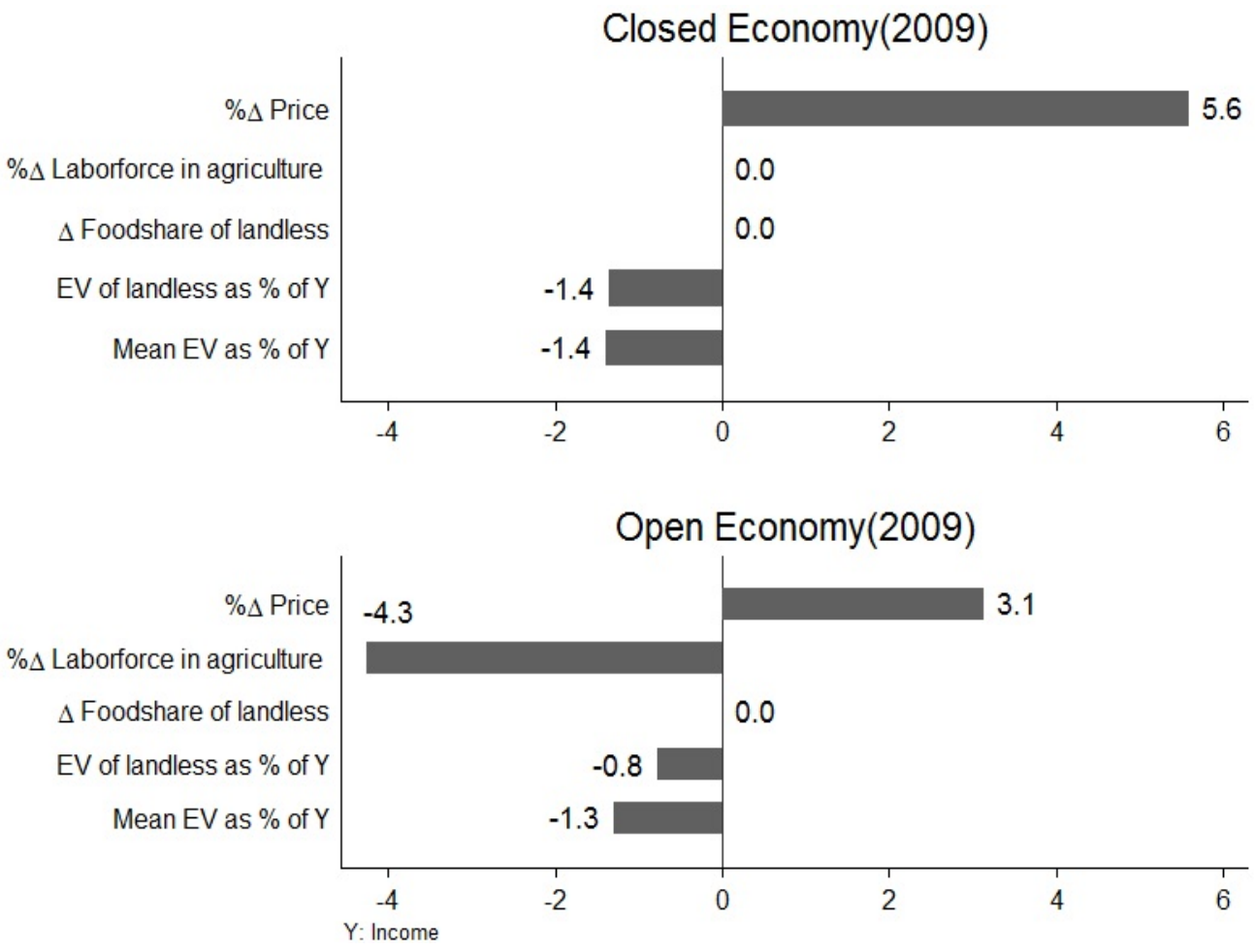


\section{Detailed description of scenarios}

In the analysis changes in climate and pollution are introduced by changing total factor productivity $\left(\theta_{F}\right)$ in the agricultural sector. According to the Fifth Assessment Report of the Intergovernmental Panel on Climate Change (IPCC), the projected change in global mean surface air temperature for the period 2016-2035 (relative to 1986-2005) is likely to be in the range $0.3-0.7^{\circ} \mathrm{C}$ (medium confidence) (See [IPCC, 2013]). The mean surface temperature increase in South Asia is likely to be in the range of $1^{\circ} \mathrm{C}$ to $1.5^{\circ} \mathrm{C}$ (medium confidence). In IPCC terminology "likely" means a two-third probability, so there is estimated to be a one-third chance that the actual temperature increase will be outside this range. Based on the existing literature on climate change impacts discussed in the introduction, we derive scenarios for India and the rest of the world by adding the estimated impacts of warming, $\mathrm{CO}_{2}$ fertilization, and ozone, on crop yields. Table (6.2) shows climate impacts in moderate and severe scenarios drawn from the literature. A moderate scenario corresponds to a onedegree increase in temperature and a severe scenario corresponds to a 2-degree increase in temperature.

A moderate scenario of a $7 \%$ fall in $\theta_{F}$ is obtained by adding a 5.5 percent fall in yields due to $1{ }^{0} \mathrm{C}$ temperature rise (as estimated by [Lobell et al., 2011] in Fig s7) and a 5 percent fall in yields due to an increase in ozone pollution in the next two decades (which is esimated by taking average of mid range loss estimates given in two studies -[Van Dingenen et al., 2009] and [Avnery et al., 2011] ) to a 3.6 percent positive effect of $\mathrm{CO}_{2}$ fertilization expected in the next two decades (1.8 percent per decade as given in [Lobell \& Gourdji, 2012]). Similarly, we obtain a severe scenario of a $13 \%$ decline in agricultural productivity in India by adding $11 \%$ fall in yields due to $2{ }^{0} \mathrm{C}$ temperature rise (obtained by doubling the $5.5 \%$ impact in moderate scenario of $1{ }^{0} \mathrm{C}$ increase in temperature) and a 6 percent fall in yields due to an increase in ozone pollution in the next two decades (which is esimated by taking average of higher end loss estimates given in two studies -[Van Dingenen et al., 2009], [Avnery et al., 2011] ) to a 3.6 percent positive effect of $\mathrm{CO}_{2}$ fertilization. A moderate scenario of a $2 \%$ fall in agricultural productivity for the rest of the world is obtained by adding $3 \%$ fall in yields (estimated based on past 3 decades crop losses estimated during 1980-2008) and a 2.2 percent fall in yields due to an increase in ozone pollution in the next two decades (which is esimated by taking the average of mid range loss estimates given in two studies -[Van Dingenen et al., 2009] and [Avnery et al., 2011]) to a 3.6 percent positive effect of $\mathrm{CO}_{2}$ fertilization. A severe scenario of $6 \%$ fall in agricultural productivity in the rest of the world is obtained by adding $6 \%$ fall in yields (doubling the impact estimated in moderate scenario) and a 3.37 percent fall in yields due to an increase in ozone pollution in the next two decades (which is esimated by 
Table D.1: General Equilibrium in Baseline Cosed and Open Economies (2030)

\begin{tabular}{lcc}
\hline & Closed Economy & Open Economy \\
\hline \multicolumn{1}{c}{ Variable } & \% Change over & \% Change over \\
& 2009 baseline & 2009 baseline \\
Food Price (Rs/kcal) & 42.9 & 15.4 \\
Annual Wage Rate (Rs) & 87.5 & 87.5 \\
Real wage Rate (Rs) & 70 & 81.74 \\
Rent per hectare (Rs) & 102 & 36.4 \\
Real Rent per hectare (Rs) & 84.14 & 29.8 \\
Food sector share (\%) & -15.6 & -36.4 \\
Food share of landless(\%) & -14.4 & -21.7 \\
Food imports as \% of food demand & - & 143 \\
Non-Food exports as \% of Non-food output & - & 60.3
\end{tabular}

Table D.2: Summarizing 7 Scenarios for 2030

\begin{tabular}{ccccc}
\hline Scenarios (2030) & Region & $N^{I}$ & $\theta_{F}^{I}$ & $\theta_{T}^{I}$ \\
\hline \hline Medium or Baseline & India & Medium & Medium & Medium \\
High population & India & High & Medium & Medium \\
Low population & India & Low & Medium & Medium \\
High productivity in agriculture & India & Medium & High & Medium \\
Low productivity in agriculture & India & Medium & Low & Medium \\
High productivity in non-agriculture & India & Medium & Medium & High \\
Low productivity in non-agriculture & India & Medium & Medium & Low
\end{tabular}

Note: In the all above scenarios it is assumed that $N^{R}, \theta_{F}^{R}$ and $\theta_{T}^{R}$ in the rest of the world grow at the medium rate.

taking average of high end loss estimates given in two studies -[Van Dingenen et al., 2009] and [Avnery et al., 2011] ) to a 3.6 percent positive effect of $\mathrm{CO}_{2}$ fertilization. We impose these scenarios on the economy when it is closed to trade and when it is open to trade. 